\title{
Risks and reliability assessment of construction processes
}

\author{
Victor Velichkin, Marina Petrochenko, Anna Gorodishenina*, and Natalia Bokovaya \\ Peter the Great St. Petersburg Polytechnic University (SPbPU); 29 Politechnicheskaya st., St. \\ Petersburg, 195251, Russian Federation
}

\begin{abstract}
Improving the reliability of the implementation of construction schedules for a complex of structures (where the level of quality, timing, and costs is taken into account) can be achieved by creating reserves: time and resources. The reserve of time, the main types of technical, labor, and material resources due to the creation of special structures is in most cases ineffective due to increased costs. Finding the most effective options for creating the corresponding structures from the standpoint of reliability and efficiency is a rather difficult task. An example is given when planning the construction of buildings of a multifunctional complex, a computational matrix is obtained for the flow organization of works. The assessment of the reliability of compliance with the directive deadline for the erection of the mainframe structures are: the critical chain method, the continuous use of resources method, the method of continuous work of front development. Keywords: construction reliability, construction process, construction, high-rise building, construction planning, construction schedule.
\end{abstract}

\section{Introduction}

Literature review on the topic of organizational and technological solutions in construction showed that a huge amount of scientific works has been done [1-6]. With the current level of improvement of construction technologies, the most important direction is to increase the quality of the final construction products while increasing labor productivity and reducing all types of associated costs and expenses.

Accordingly, the acceleration of construction processes and an increase in their quality significantly increase the risks of violation of technological standards, the risks of delays in the execution of work and reduce the reliability of the implementation of planned construction indicators. In this regard, it becomes advisable to use various preventive measures to ensure a sufficient level of reliability of compliance with the established construction parameters. In the construction of complex structures, various methods of improving the reliability of construction processes can be considered: organizational, technological, structural, informational, managerial, etc. [7-11].

These methods can be applied both in the process of developing timetables and in developing management decisions. These preliminary activities include:

- identification of methods for organizing construction processes that significantly reduce the risks of reducing the quality of the resulting products and increase reliability of scheduled dates;

\footnotetext{
* Corresponding author: gorodish_ayu@spbstu.ru
} 
- formation of technological options that ensure the availability of time and production resources at each stage of construction, which helps to eliminate emerging failures in work and increase the reliability of the flow of construction processes;

- development and preliminary inclusion of redundant technological and resource structures in the calendar plans and current management solutions to stabilize the flow of production processes;

- introduction into management practice of monitoring systems for current production processes in terms of quality and timeliness of the creation of construction products;

- creation of managing hierarchical structures in the bodies of construction companies, ensuring timely response to emerging risks and failures, to possible deviations from the planned pace of construction.

The inclusion of these preventive measures in the complex technological process of construction of building complexes requires development of number of theoretical problems. The primary task is to determine a set of process parameters assessing the possibility of risks and failures, the timeliness of completing the planned stages with a given level of quality. The next task is to determine the unacceptable level of risks and the likelihood of their occurrence based on the set of established process indicators. Next, you should determine the level of reliability of the entire construction process. At the final stage, it is necessary to consider possible preliminary (mentioned above) measures and the level of their strengthening to achieve the required level of predicted reliability.

\section{Materials and methods}

The tasks include the need to develop methods for assessing the effectiveness of measures used to improve the reliability of the construction process. In the form of an indicator of the effectiveness of the reliability of construction processes, one can use the level of shortening the construction time, reducing the costs of organizing construction production, increasing the quality level of construction products. Based on applied performance indicators, it is necessary to formulate criteria for optimizing decisions on the implementation of possible measures to improve reliability while reducing the likelihood of possible risks. As a rule, these criteria form an objective function for the formation of the best or optimal solutions to achieve the specified levels of reliability in terms of quality, timing and costs.

The significant variety of methods and models [12-15] used for calculating and optimizing the work organization [16] requires a detailed study of the possibilities for achieving a high level of construction processes reliability. Improving the reliability of the implementation of construction schedules for a complex of structures (where the level of quality, timing and costs is taken into account) can be achieved by creating reserves of time and resources [17-19]. Reserves of time and resources for work are formed in one volume or another when forming possible methods of organizing construction. Reserving both time and the main types of technical, labor and material resources by creating special structures in most cases from the point of view of increasing costs is ineffective. The search and formation of the most effective options for creating the corresponding structures from the standpoint of reliability and efficiency is a rather difficult task.

The construction of redundant structures that contribute to a tangible increase in reliability can be carried out by building organizational and technological structures for the implementation of complexes of construction and installation works.

\section{Results and discussion}


If we consider reliability $(\boldsymbol{W})$ as the probability of completing work packages on schedule, then the reliability function should take. In addition to the general probability of the process $(\boldsymbol{p})$, there are some parameters: the method of organizing work $\left(\boldsymbol{T}_{\boldsymbol{m}}\right)$, available time reserves $\left(\boldsymbol{R}_{\boldsymbol{u}}\right)$, the presence of redundant structures $\left(\boldsymbol{C}_{\boldsymbol{t}}\right)$, indicators of the control system $\left(\boldsymbol{P}_{\boldsymbol{c}}\right)$, the compensation degree for external influences $(\boldsymbol{\varepsilon})$.

In general, the reliability function can be represented as the following expression: Equations should be centred and should be numbered with the number on the right-hand side.

$$
W=\varphi\left(p, T_{m}, R_{u}, C_{t}, P_{c}, \varepsilon\right)
$$

Considering the influence of some variables on the value of the probability indicator, it is fair to define the probability as a function of the variables $T_{m}$ and $R_{u}$, which determine the duration of the complex of works:

$$
p=\gamma\left(T_{m}, R_{u}\right)
$$

Then, instead of the expression (1), one should apply:

$$
W=\varphi\left(p, C_{t}, P_{c}, \varepsilon\right)
$$

Based on the studies carried out, it can be considered that the main direction of ensuring the required level of construction processes reliability at the planning stage is the creation of an appropriate work organization. It also includes the formation of the method with maximum time reserves for several works and the entire complex (indicators $T_{m}$ and $R_{u}$ ) and processes duplication (indicator $C_{t}$ ). It is necessary to take a specific form of the probability distribution function to assess the level of reliability. The efficiency parameters of the control system $\left(P_{c}\right)$ and the quality of arising delays (failures) elimination should be introduced.

It is necessary to use several methods of stream works organization [12-15] and take the beta distribution function for reliability calculations with the introduction of one or two parameters to take into account the quality of control actions. It is most expedient to build construction processes according to the critical path method and the method of continuous use of labor and technical resources. As a kind of beta distribution, the probability of density function of a random variable for the completion date of construction processes [20] can be taken in the following general form:

$$
\Psi(x)=\frac{(\xi+1)(\lambda+2)(\mu+3)}{2 \cdot(b-a)^{\frac{(\xi+\lambda+\mu)}{3}+3}} \cdot(x-a)^{\frac{(\xi+\lambda+\mu)}{3}+1} \cdot(b-x)^{2}
$$

where $\Psi(x)$ - density frequency function of a random variable;

$x$ - value of the random variable deadline milestone;

$a-$ minimum possible deadline of the milestone;

$b$ - maximum possible end date of the milestone;

$\xi$ - a function parameter, that characterizes the efficiency of the control system;

$\lambda$ - a parameter, that takes into account the impact of time reserves on management efficiency:

$$
\lambda=\xi+\frac{0.1 \cdot R}{T}
$$

$\mu$ - a parameter, that takes into account the influence of the management structure on its effectiveness:

$$
\mu=\xi+0.1 \cdot S
$$

The completion probability of the set of tasks for given optimistic and pessimistic estimates for any period can be calculated by the expression: 


$$
\rho(T)=0.5 \alpha^{\frac{(\xi+\lambda+\mu)}{3}+1}\left[\alpha^{2}(\xi+1)(\lambda+2)-2 \alpha(\xi+1)(\mu+3)+(\lambda+2)(\mu+3)\right]
$$

where $\rho(T)$ - the probability of execution the tasks in the period T;

$$
\alpha=\frac{T_{d}-a}{b-a}
$$

It is possible to build a planning structure that allows to transfer construction processes at the necessary time from one method to another during the forming several methods of organizing the work. Such a planned structure ensures duplication of the construction process, which can significantly increase the reliability to meet the established deadlines. In this case, the reliability (probability) can be determined in a known way:

$$
W=1-\prod_{i=1}^{n}\left(1-p_{i}\right)
$$

where $p_{i}$ - the probability of meeting the planned deadlines for the $i$-th method of work organization.

As an example, we can determine the reliability of compliance with the directive deadline for the erection of frame structures in the construction of a multifunctional complex.

\begin{tabular}{|c|c|c|c|c|c|c|}
\hline Capture & Earthwork & $\begin{array}{l}\text { Installation of } \\
\text { reinforced } \\
\text { concrete } \\
\text { foundations }\end{array}$ & $\begin{array}{l}\text { Installation } \\
\text { of } \\
\text { undergroun } \\
\text { d structures }\end{array}$ & $\begin{array}{l}\text { Installation } \\
\text { of the } \\
\text { abovegroun } \\
\text { d frame }\end{array}$ & $\begin{array}{l}\text { Installation } \\
\text { of } \\
\text { enclosing } \\
\text { panels }\end{array}$ & $\begin{array}{l}\text { Installation } \\
\text { of concrete } \\
\text { floors and } \\
\text { screeds }\end{array}$ \\
\hline 1 & $\begin{array}{c}10 \\
0-10 \\
0-10 \\
0=10\end{array}$ & $\begin{array}{c}8 \\
10-18 \\
16-26 \\
10=18\end{array}$ & $\begin{array}{c}11 \\
18-29 \\
26-37 \\
18=29\end{array}$ & $\begin{array}{c}32 \\
29-61 \\
37-69 \\
29=61\end{array}$ & $\begin{array}{c}17 \\
61-78 \\
232-249 \\
61=78\end{array}$ & $\begin{array}{c}12 \\
78-90 \\
257-269 \\
78=90\end{array}$ \\
\hline 2 & $\begin{array}{c}13 \\
10-23 \\
10-23 \\
24=37\end{array}$ & $\begin{array}{c}10 \\
23-33 \\
26-36 \\
37=47\end{array}$ & $\begin{array}{c}14 \\
33-47 \\
37-51 \\
47=61\end{array}$ & $\begin{array}{c}80 \\
61-141 \\
69-149 \\
61=141\end{array}$ & $\begin{array}{c}20 \\
141-161 \\
249-269 \\
141=161\end{array}$ & $\begin{array}{c}21 \\
161-182 \\
269-290 \\
161=182\end{array}$ \\
\hline 3 & $\begin{array}{c}11 \\
23-34 \\
23-34 \\
105=116\end{array}$ & $\begin{array}{c}7 \\
34-41 \\
36-43 \\
116=123\end{array}$ & $\begin{array}{c}18 \\
47-65 \\
51-69 \\
123=141\end{array}$ & $\begin{array}{c}110 \\
141-251 \\
149-259 \\
141=251\end{array}$ & $\begin{array}{c}16 \\
251-267 \\
269-285 \\
251=267\end{array}$ & $\begin{array}{c}29 \\
267-296 \\
290-319 \\
267=296\end{array}$ \\
\hline 4 & $\begin{array}{c}9 \\
34-43 \\
34-43 \\
234=243\end{array}$ & $\begin{array}{c}4 \\
43-47 \\
43-47 \\
243=247\end{array}$ & $\begin{array}{c}9 \\
65-74 \\
69-78 \\
247=256\end{array}$ & $\begin{array}{c}26 \\
251-277 \\
259-285 \\
256=282\end{array}$ & $\begin{array}{c}14 \\
277-291 \\
285-299 \\
282=296\end{array}$ & $\begin{array}{c}8 \\
296-304 \\
319-327 \\
296=304\end{array}$ \\
\hline
\end{tabular}

The calculation matrix for the stream organization of work is presented in the Table 1.

Table 1. Matrix for the stream organization of work

Note. The first line in the table is the duration of work in days. The second line is the start and end dates for the critical work method. The third line is the start and end dates for the continuous use of resources. The fourth line is the start and end dates of work according to the method of continuous work fronts development. 
According to this table, we get the total idle time of resources and work fronts equal to 625 days for the critical work method.

For a design example, we take $\xi=1$ with weekly control and control actions.

Then $\lambda=1+\frac{0.1 \cdot 625}{304}=1.206$ and $\mu=1+0.1 \cdot 3=1.3$, since we consider the management structure with the possibility of using three methods of organizing work.

For the continuous use of resources method, we obtain a total idle time of resources and work fronts equal to 629 days:

$$
\lambda=1.192 \text { and } \mu=1+0.1 \cdot 3=1.3
$$

For the method of continuous work fronts development, we obtain the total idle time of resources and work fronts equal to 923 days:

$$
\lambda=1.304 \text { and } \mu=1+0.1 \cdot 3=1.3
$$

The influence of time reserves and the management structure on the efficiency of the control system functioning according to experimental data is estimated at $7-18 \%$ to increase the probability to meet the design deadlines for construction. In this regard, the design example, an average value of $10 \%$ is taken.

Now we estimate the reliability of compliance with the directive term for the construction of the main frame structures, $a=T \cdot 0.85$ and $b=T \cdot 1.3, \mathrm{Td}=332$ days.

1. The critical work method.

$T=304$ (from the Table 1)

$a=304 \cdot 0.85=258$

$b=304 \cdot 1.3=395$

$\alpha=\frac{332-258}{395-258}=0.54$

$\rho\left(T_{d}\right)=0.5 \cdot 0.54^{2.17}\left[0.54^{2} \cdot 2 \cdot 3.206-2 \cdot 0.54 \cdot 2 \cdot 4.3+3.206 \cdot 4.3\right]=0.83$

2. The continuous use of resources method.

$T=327$ (from the Table 1)

$a=327 \cdot 0.85=278$

$b=327 \cdot 1.3=425$

$\alpha=\frac{332-278}{425-278}=0.37$

$\rho\left(T_{d}\right)=0.5 \cdot 0.37^{2.16}\left[0.37^{2} \cdot 2 \cdot 3.192-2 \cdot 0.37 \cdot 2 \cdot 4.3+3.192 \cdot 4.3\right]=0.47$

3. The method of continuous work fronts development.

$T=304$ (from the Table 1)

$a=304 \cdot 0.85=258$

$b=304 \cdot 1.3=395$

$\alpha=\frac{332-258}{395-258}=0.54$

$\rho\left(T_{d}\right)=0.5 \cdot 0.54^{2.2}\left[0.54^{2} \cdot 2 \cdot 3.304-2 \cdot 0.54 \cdot 2 \cdot 4.3+3.304 \cdot 4.3\right]=0.88$

4. Determine the reliability of compliance with the directive deadline for the construction of the main frame structures

$$
W=1-(1-0.83) \cdot(1-0.47) \cdot(1-0.88)=0.99
$$


Thus, it is possible to achieve almost complete reliability of compliance with the established construction deadlines by taking into account possible reserves of time and using the main possible methods of organizing work in the management structure. Even using only two methods (the critical work method and the continuous use of resources method) it is possible to get a reliability of $0.95-0.96$.

\section{Conclusions}

1. The main direction of ensuring the required reliability level for construction processes at the planning stage is the creation the appropriate work organization (maximum time reserve for several works and the entire complex, duplication of processes).

2. Development of theoretical foundations and methods of probability values calculating for specific planning decisions, taking into account this approach, can provide a high level of reliability in the implementation of construction processes.

3. The method of temporary reservation:

- increases the organizational and technological reliability of construction;

- allows to level the deviations from the schedule, that have arisen in the construction process;

- reduces the risks of delays the terms of construction objects.

4. The use of methods for duplicating construction processes, reserving the main types of resources, creating a redundant structure is an urgent way to improve the construction reliability at the planning stage.

\section{References}

1. A.A. Lapidus, Efficiency Potential of Management and Technical Solutions for a Construction Object in Proceedings of the Moscow State University of Civil Engineering, No. 1, pp. 175-180 (2014) DOI: $10.22227 / 1997-0935.2014 .1 .175-180$

2. A.V. Ginzburg, Organizational and Technological Reliability of Construction. System Engineering, ed. A.A. Gusakov, Moscow: New Millennium Foundation, 768 p. (2002)

3. A.A. Gusakov, A.V. Ginzburg, S.A. Veremeenko et al. Organizational and Technological Reliability of Construction Systems, Moscow, SvR-Argus Publ., 472 p. (1994)

4. B. Fleischmann, H. Meyr and M. Wagner, "Advanced Planning", In Stadtler, H. \& Kilger, C. (Eds.), Supply Chain Management and Advanced Planning, Concepts, Models, Software, and Case Studies, 4th ed, Springer, Berlin. (2008)

5. Yichuan Deng, Jack C.P., Cheng Construction Supply Chain Coordination Leveraging 4D BIM and GIS Integration, 20th World Building Congress, 12 p. (2016)

6. A. E. Agwua, A. Labiba, Sara Hadleigh-Dunnb, Disaster prevention through a harmonized framework for high reliability organisations in Safety Science 111, pp. 298-312 (2019) https://doi.org/10.1016/j.ssci.2018.09.005

7. O.I. Nedavny, S.V. Bazilevich, S.M. Kuznetsov, Assessment of organizational and technological reliability of project Construction in Systems. Methods. Technologies. No. 2 (18), pp. 137-141 (2013) 
8. P.B. Zhavnerov, A.V. Ginzburg, Using Structural Actions to Improve Organizational and Technological Reliability of Construction Activities in Proceedings of Moscow State University of Civil Engineering. No. 3, pp. 196-200 (2013)

9. E.A. Kotova, Yu.P. Ermakova, Methods for increasing the organizational and technological reliability of the construction process in Materials of the International Scientific and Practical Conference of Young Researchers. DI. Mendeleev, dedicated to the 10th anniversary of the Institute of Industrial Technologies and Engineering. Publisher: Federal State Budget Educational Institution of Higher Education «Industrial University of Tyumen», pp. 231-234 (2019)

10. A.S. Bolotova, A.V. Ginzburg, Analysis of Organizational and Technological Reliability of Monolithic Construction in Journal of Economy and Entrepreneurship, No. 10-1 (75-1), pp. 647-651 (2016)

11. E.V. Zanina, V.V. Sokolnikov, Methods of increasing the organizational and technological reliability of construction in Technology and organization of construction. Materials of the I All-Russian interuniversity scientific-practical conference of young scientists, dedicated to the 80th anniversary of the founding of the department "Construction production", pp. 168-171 (2020)

12. G.I. Abdullayev, V.Z. Velichkin, T.N. Soldatenko, The organizational and technological reliability improvement in construction by using failure prediction method in Magazine of Civil Engineering, No. 3 (38), pp. 43-50 (2013)

13. I.I. Vladimirov, Application of a matrix algorithm for calculating the duration of construction of monolithic buildings using the flow organization of construction production in Science and business: ways of development, No. 4 (82), pp. 89-96 (2018)

14. S.V. Bovteev, Calculation of the parameters of the streamline work organization by the critical path method in Bulletin of Civil Engineers, No. 15 (3), pp. 90-97 (2018) DOI: 10.23968/1999-5571-2018-15-3-90-97.

15. A. Mailyan, G. Afanasiev, D. Antoniadi, R. Petrosyan, Formation of optimal performance of works during establishment of the complex of objects optimal sequence of establishing objects complex building in IOP Conference Series: Materials Science and Engineering, Vol. 896 (1) (2020)

DOI: $10.1088 / 1757-899 X / 896 / 1 / 012053$

16. M. Kuzhin, M. Akimockina, Optimization of construction parameters using resource scheduling in E3S Web of Conferences, Vol. 97 (2019)

DOI:10.1051/e3sconf/20199706030

17. L.V. Volkova, The influence of probabilistic conditions on organizational and technological solutions at construction of residential buildings in Bulletin of Civil Engineers, Vol. 4 (51), pp. 87-95 (2015)

18. N.Yu. Startseva, Modeling the parameters of organizational and technological building reliability of gas industry extended objects in Bulletin of Civil Engineers, No. 2 (49), pp. 96-101 (2015)

19. S.V. Nikonorov, A.A. Melnik, Improvement of Organizational and Technological Reliability of Construction in Modern Conditions in Bulletin of the South Ural State University, Ser. Construction Engineering and Architecture, Vol. 19, No. 3, pp. 19-23 (2019)

DOI:10.14529/build190303 
20. D.R. Absalyamov, Improving the engineering systems reliability by formalizing the failure search in Magazine of Civil Engineering, No. 2, pp. 39-47 (2012) 